\title{
Impact of Vision Based Recruitment on Organization's Performance in Pakistan
}

\author{
Ahsan Khan (Corresponding author) \\ Karachi University Business School, University of Karachi \\ KU Circular Road, University of Karachi, Karachi, Pakistan \\ E-mail: unknownfabulous@yahoo.com \\ Dr. Danish Ahmed Siddiqui \\ Karachi University Business School, University of Karachi \\ KU Circular Road, University of Karachi, Karachi, Pakistan \\ E-mail: daanish79@hotmail.com
}

Received: Oct. 8, 2018 Accepted: Oct. 29, 2018 Online published: Nov. 11, 2018

doi:10.5296/ijhrs.v8i4.13803 URL: https://doi.org/10.5296/ijhrs.v8i4.13803

\begin{abstract}
The aim of this study is to investigate the impact of vision-based recruitment on organization performance. This study will further analyze the attributes of vision along with its mediating effects particularly onto the recruitment process in an organization. For this purpose, a quantitative method was used collected data from 102 employees for further investigation who works in different sector i.e. public and private sectors in Pakistan. In this way, this study finds different attributes of vision such as sharing, clarity, and stability that have compelling effects on an organization's performance. It has been observed that vision based components significantly influence the organization performance.
\end{abstract}

Keywords: organizational performance, recruitment, vision based recruitment, visionary recruitment, VBR

\section{Introduction}

It has been signified that the vision is the most important factor that affects the overall organization performance (Khan \& Rasheed, 2015). Similarly, recruitment is also exceptionally basic and specialized process for every organization to become successful because having the proper appointed staff sustains and enhance organization's performance. 
This means that the organization recruit the right person for the right job according to his/her skills. The impact of an organization's recruitment framework impact on main concern business results, for example as productivity, profitability, and financial performance. A fulfilled and skillful staff brings more satisfied clients who are the main contributor to remarkable organizational execution. Despite the fact that extensive evaluation of statistics and research studies (literature) has acknowledged that there is hardly any observation that has investigated directly on the impact of vision based recruitment on the organization's performance.

Recruitment is an elementary matter that needs to be practiced in any organization by HRM that influences the organization towards the prosperity. Recruitment is the strategy of finding and obtaining (hiring) the best-qualified candidate (inside or outside from organization) for a business opportunity, in a favorable and useful manner. The recruitment strategy combines the different requirements of a business for which it is necessary to assign experts or skillful person to that action. This will be done with the help of selecting and screening employees with particular required skills for any specific task. It has a real effect on the organization's outcomes.

A vision statement is an optimistic account of what an organization must want to accomplish within a specific time. When evaluating people seeking work, the staff must be conditional. The employee's specification or candidate's profile is sometimes necessary to clarify the characteristics of the candidates for the job sought. Therefore, staff profiles become a summary of the most important knowledge, skills, and personal attributes that are required of a successful candidate, which makes the task an acceptable level of performance. The characteristics of the personnel, due to their relevance, depend on the nature and scope of the work as described in the job description and, if necessary, they should seek comments from the corresponding Director. Of course, the nature of the work will determine the level of knowledge and skills required, but the work will be applied in a specific social context, so it is important to have a perspective of the type of personality characteristics that will allow the manager to comply with the obsession of the newcomer.

It is a chance that all staff have the same course then it is the evident thing to have higher performance outcomes.

\subsection{Vision with Recruitment}

Vision based recruitment means hiring someone regarding his or her vision. It really does not mean that his or her qualification, skills, and other abilities are not taken into consideration but the main focus in vision based recruitment is about vision. Vision means ideas, forecasting the future, planning, understanding of many issues and many other qualities of leadership required for teamwork, guidance and taking his/her subordinates. It can also say that the followers on such a path that organization first achieve its goals one by one and later achieve its whole target and complete its mission.

Vision based recruitment means hiring someone regarding his or her vision. It really does not mean that his or her qualification, skills, and other abilities are not taken into consideration 
but the main focus in vision based recruitment is about vision. Vision means ideas, forecasting the future, planning, understanding of many issues and many other qualities of leadership required for teamwork, guidance and taking his/her subordinates. It can also say that the followers on such a path that organization first achieve its goals one by one and later achieve its whole target and complete its mission.

The best example of vision-based recruitment is an election. Here people recruit a person as a leader considering his or her vision. In previous sentence word "leader" is used not because vision based recruitment is only done in politics and elections for some kind of government position like P.M. or other seats of General Assembly of Provincial Assembly. The leader is the person who is followed by people and contains a vision to guide the right path to people in order to fulfil the organizational mission.

\subsection{Scope of Vision Based Recruitment}

There is no doubt that vision based Recruitment contains very narrow scope because this type of recruitment is only effective for those positions in which Strategic Decision Making involve. On the ground level, this type of recruitment is not so much effective because of qualification and technical skills required for the specific job. It is must for Strategic Decision Makers to have a very vast vision; hence, it helps to create plans, strategic infrastructures and shows others making strategic infrastructures effectively. Many people think that Vision Based Recruitment does not require qualification and skills but this concept is right to a limited extent. The leader of the decision maker cannot take the right decision at the right time if they do not know the problem and its solutions with its pros and cons. The reason to say that "concept is right to a limited extent" is that it is seen many times that many of the great names who did not have technical knowledge proved themselves to be the great strategic managers, e.g. Steve Jobs and Bill Gates (Imran, Tanveer, \& Studies, 2015).

\subsection{Problem Statement}

It has been observed that some organizations hire the individuals who are not capable of the particular skills for specific tasks. Moreover, it has been also signified that sometimes employees are not able to work according to the vision of an organization. This may impact on the organizational performance. Hence, it is necessary to find the factors of vision based recruitment in an organization along with its influence on its performance.

\subsection{Objective of Research}

(i) The study is intended for examining an understanding of the relationship between vision-based recruitment in the organization and its impact on the work performance of an organization's workforce.

(ii) To explore the impact which reflects when the vision is aligned with the recruitment process and its effect on an organization's performance.

(iii) To find out the vision attributes in the recruitment of employees and getting high-end results. 


\section{Literature Review}

\subsection{Concepts and Operational Concepts}

The Fraser model, as Rodger does, is an important contribution to recruitment and selection in organizations. It provides a practical framework to ensure that voters make reasonably consistent comparisons between candidates (Ekwoaba, Ikeije, \& Ufoma, 2015). What is important here is that the Organization is trying to create a greater element of predictability and control, combining personal judgment with individual prejudices, in the event that substantive knowledge can be achieved in a short time. Presently employers and top-level managers need to realize that how they can impact adherents or workers to submit them with the vision of the organization with the rationality (Saleem \& Khurshid, 2014).

Top-level managers simply need to impart the vision to their staff and top administration gives the central focuses to the senior officials of the association to clarify the normal future achievement of the company (Asrar-ul-Haq, Kuchinke, \& Iqbal, 2017). Vision should be organized on the establishment of some fundamental columns are as per the following.

\subsubsection{Clarity of Vision}

The finest method to impart (share) vision' to staff is a simple and brief which is not complicated in nature in words (statement) utilizing as a part of the vision must be straightforward and must be least in mean the better comprehension of a worker (Azeem, Abrar, Bashir, Zubair, \& Management, 2015). A dream can be said clearly, on the off chance that it has 10 to 12 words and can be imparted in a brief era, and should deliver the concept within less time (within minutes).

\subsubsection{Future Orientation and Desirability of Vision}

The vision which attracts people and engages team into working in a positive way establishes an organization' and directs the organization toward the charming or magnificent future of a company or organization who wants to win the hearts of staff and can ready to win the trust of the general population working in an organization (Ekwoaba et al., 2015). What's more, in the long run, that can make the optimistic future state picture of an organization in the brain of workers with the help of some acknowledged wisdom that offers would like to subordinates employees which relate their supportability and for sustained continuity of the organization (Imran et al., 2015).

\subsubsection{Vision Stability}

It implies that vision isn't for one-time objective and target once accomplished the specific goal and after that vision repetitive, in the interim, it must be steady and predictable over the time-frame (Asrar-ul-Haq \& Kuchinke, 2016).

\subsubsection{Vision Sharing}

Vision sharing help to reinforce the worker responsibility and offer the hierarchical qualities with a specific end goal to bring great and attractive execution of an organization nearby future (Ahmed, Fiaz, \& Shoaib, 2015). 


\subsubsection{Recruitment}

The path towards finding and acquiring the best-qualified candidate for a business or employment opportunity is a helpful and fiscally sharp way. Recruitment methodology consolidates dismembering the essentials of attracting new candidates for the activity, screening and picking applicant or candidates, obtaining, and planning the new staff to the organization (Sabharwal, 2014).

\subsubsection{Organizational Performance}

An examination of an organization's performance is when contrasted with objectives and destinations i.e. organization's milestones (Haroon, Shariff, \& Law, 2016). Inside corporate organizations, there are three essential results examined: money related performance, market or showcase performance and investor esteem execution (sometimes, creation limit execution might be breaking down) (Asrar-ul-Haq \& Kuchinke, 2016).

\subsection{Vision with Recruitment}

To convey considerable estimations of the organization vision assumes a basic part in it. The thought of center estimations of an organization and the targets and purposes stay steady which demonstrates the dependability of vision. The little arrangement of vision with hierarchical qualities is getting to be sketchy. The center estimations of an organization have been perceived as strong beliefs, convictions, methods of insight, and philosophies; inevitably, it has acknowledged because of the organization's vision (Asrar-ul-Haq et al., 2017).

If the employees are recruited by long and broad vision it will produce a modest contribution of staff in the work culture of the organization; it turns into the reason for unacceptable (unsatisfactory) staff (Hameed, Ramzan, Zubair, \& Science, 2014). Visionary leaders and top managers figure and actualize the vision as indicated by the procedure of the company or organization, which interfaces the representatives with authoritative center qualities, theory and belief system of the organization (Sabharwal, 2014). The administration ought to have the ability to make vision that staff working in the organization can accept and demonstrates their possession (Hassan \& Sciences, 2016). In the interim vision gives the practical insight to fulfill the aim that verbalized by the appealing initiative and in the meantime. It identifies where they are presently and where they would be later on.

However, top managers or directors must have two noteworthy measurements the center rationality and hopeful future condition of the organization (Hafeez, Akbar, \& Strategy, 2015). Vision likewise depicts the credible, motivating, level-headed, extraordinary and clarification of the preferred spot (position) of the organization overcurrent state (Awan \& Farhan, 2016). Apparently, the principal competency of an organization relies on capable administration, and initiative might be depicted in vision (Awan \& Farhan, 2016). The vision demonstrates the direction that how a company can expand its magnitude and size of progress and develops in an efficient manner (Ahmed et al., 2015).

However, the vision portrays passage to the future accomplishment of the company's goal (Arshad, Azhar, \& Khawaja, 2014). The vision is a thought that must impart and share with 
workers keeping in mind the end goal to empower employees and staff to achieve the future state of company's goal, whereas the vision is the main aspect for the top management to show bright of the picture to staff in the organization (Rana, Malik, Finance, \& Management, 2017). In any case, this inquiry is still early stages, which property of vision decidedly effects on employee's expectations fulfillment (Arshad et al., 2014).

Since 1980, the advancing speculations of leadership vision moving the worldview of pioneer properties into the explanation of vision, for the most part, the organizations are confronting experiencing changes concerning up a degree of advances. Taking into account the overall goal is to accomplish which proceeded with the upper hand a vision must be expressed by the fundamental traits of winning or successful administration or management (Iqbal, Nadeem, Zaheer, \& Review, 2015). Nevertheless, numerous organizations' administration is in search of haring the vision in a successful route for workers, which ensured the manageable advancement and long-haul development for the organization (Awan \& Farhan, 2016).

(Rana et al., 2017) defines employment as securing the right people to fill certain people. This can be in the form of advertising for large groups of employees or for the unqualified person into a specific job. This means that not everyone with qualification is eligible to make an appointment. The HR management must choose the right candidate for a given post. According to (Iqbal et al., 2015), recruitment is a process to attract people adequately, in sufficient quantities and with appropriate qualifications, to develop an established interest and to encourage them to apply for jobs (Aslam, Ilyas, Imran, \& Rahman, 2016). This clearly shows that the recruitment practices are not done at a certain time, not only during the year but when necessary (Pak \& Kim, 2018).

Consider the major goal is to make the common future without bounds by framing the compelling vision a few researchers distinguished numerous qualities of a dream. To the extent, the creating and sharing of vision are 2 elementary activities of successful administrationไmanagement and the following stages are dispersal of the vision amongst staff to understand in a better direction (Altinay, Madanoglu, De Vita, Arasli, \& Ekinci, 2016). In addition, it has been signified that numerous places of interest in relation to the vision based recruitment impacts altogether on organization's performance (Bisharat, Obeidat, Tarhini, Mukattash, \& Management, 2016).

Unfortunately, the vision has turned into mishandling aspect considered in any organization, and undesirably the slightest comprehended expression of the goals structured in an organization (Rana et al., 2017). The broad writing audit of the influence uncovers noteworthy traits of a viable vision; hence, it is necessary to make vision clear and easy to understand for both the organization and employees of the organization (Dhar, Rahouma, Masruki, \& Absar, 2017). It has been investigated that the vision based recruitment correspondingly keeping identified the end goal to make more appealing standards and estimations of the organization (Aslam et al., 2016). Therefore, they suggested some key develops to figure the visions that are considered as the controlling standards for a pioneer and top leaders or top management to detail (Rizwan, Khan, Nadeem, \& Abbas, 2016).

The desirability in vision essentially enhances worker confidence, in the long run, it fulfills a 
representative (Rana et al., 2017). With a specific end goal to expand the viability of an organization, a dream must be steady and it is more engaged to the organization for their advancement (Arshad et al., 2014).

Future introduction of the vision and organization's performance is interlinked, the administration or management with vision having above traits/qualities like vision sharing, clarity, vision future orientation, captivating and strength of vision engage himself towards fill in as well as enables their representatives(employees) toward working culture which at last enhance and improve the organizational performance (Awan \& Farhan, 2016).

\subsection{Vision Clarity in an Organization}

The finest method to impart vision to the staff with basic dialect and the words utilizing as a part of the vision must be straightforward and less as feasible for the better comprehension of a staff working in the organization. Clarity or visibility of the vision in various parts of organization addresses to staff and gets them with organization towards clear and satisfactory way where it must move. The words in vision explanation should genuine implication (Hafeez et al., 2015). Thusly, a vision imparted (shared with the organization) or created must be short and concise.

However, a short declaration of vision can be depicted in a nutshell time (Yousaf, Yang, \& Sanders, 2015). A short vision verbalization infers that contains most outrageous 11 to 20 words. A short vision makes the motivation towards fiscal self-excitement to experts, which updates the organization's execution. It has been signified that the concise vision is undeniable, engaged and justifiable to all the staff and workers of the organization. Therefore, it is able to ought to better performance if the enrolment is occurring by centering the organization's vision, which eventually would be the reason for the top of the line organization's performance (Hafeez et al., 2015). In the meantime, motivated staff is more fulfilled towards the work and day-by-day errand allocated by the top management (Altinay et al., 2016).

The swiftness of the vision is not sufficient when the organizations are extremely powerful, intuitive, and responsive concerning changes in innovation, information societies, and linkages around the world, so a pioneer must drive the supporters towards the correct heading and it ought to for him to give them essential issue (Altinay et al., 2016). With the conciseness of vision, a dream must have the embodiment of clarity in it that it must be particular, identifiable or clear for a specific future time (Altinay et al., 2016). Meanwhile, it must be comprehended and acknowledged for every one of the staff at every grade of management (Iqbal et al., 2015).

\subsection{Future Orientation, Desirability, and Challenge}

Additionally, a viable vision has to be future arranged with the quality of clearness, and additionally, future situated vision guarantees the staff working in the organization about organization's long drag maintainability with progressive development and advancement. Middle-level directors or managers have firm trusted that vision imparted to other individuals from the company or organization must be captivating (Sabharwal, 2014). To explain an 
attractive, sensible, and tenable eventual fate of any company that would be conceivable if administration/top-level management has clear and sustained future arranged vision for his adherents/employees (Arshad et al., 2014).

In short, a vision must be future situated. However, another idea of vision is to accumulate all components from current continuous situations and forerunners of business (Azeem et al., 2015). Afterwards, coordinate them for the suspicion and direction for the future activities and rules. Another broad distinction made by the organization accompanied by detailing of vision is to structure the useful change in the announcement or verbal correspondence of vision from the present position to the future position of an association (Hassan \& Sciences, 2016). This long drag steadiness and maintainability of organization might enhance the trust of workers over the association (Sabharwal, 2014). Moreover, it expands the representative fulfillment and decrease the turnover rate of skilled representatives and upgrade the organization's performance in the long run (Ahmed et al., 2015).

Transformational management can plan the moving vision to interest the employees or staff in the vast organization, where the work drive is more extensive as a contrast with the small organizations and also to fulfill the workers (Sabharwal, 2014). The top managers with giving reasonable vision inspiration to key constituents of the organization by saying what cannot avoid being what is great either awful, now or how it would be upgraded in the nearby future (Azeem et al., 2015). To keep the company on immense improvement, directors need to interface with key constitutes particularly customers, staff, and accessories of the business and more especially the fulfilled staff through a spurring and attractive organizational vision (Bisharat et al., 2016). This will significantly drive every individual's desire.

Nevertheless, the inadequate vision could never have perceived the new difficulties and potential outcomes of new organizations for the development and best execution of an organization. Therefore, a testing vision challenges the inventive and imaginative abilities of the staff and it purposefully constrains them to accomplish something exceptional (Azeem et al., 2015). Convincingly it altogether impacts on the organization's performance.

\subsection{Vision Stability}

It is vital to adjust and settle the vision from the starting phase of recruiting workers so the organization will accomplish maximum performance. A compelling vision not influenced by the dynamic and massive changes in the innovation and also in business. The unsteady dream of any organization demonstrates the lesser measure of responsibility and trustworthiness with management and organization's vision. The stable vision shows the general thought without limiting condition of the organization and it does not change additional time altogether (Haroon et al., 2016).

With dependability and future introduction a fantasy (vision) must be detached, it infers it is not for one goal and for one time as the goal achieved and a short time later the purpose behind vision should not be done likewise a dream should have the dynamic and bearing trademark towards the change. In this way, they would pass on to the world about the explanation behind imminence of the association (Asrar-ul-Haq et al., 2017). Hence, the 
HRM must have an unfaltering and disengaged vision and they ought to perceive what should change and what should not change with the modification in condition and advancement. However, persistent change in the objectives may purpose behind the disappointment of authorities and it drives the association towards fall in an organization (Hameed et al., 2014). So far, the accomplishment and dissatisfaction of the association depend on these main viewpoints.

\subsection{Gap Analysis}

Higher management and managers of any company motivate supporters and staff to work by sharing and imparting the vision of the organization. Viable characteristics of vision fundamentally effect on the organization's performance by imparting the vision to the functions of the organization. A positive and direct relationship was detected among the wander development in term of high deals or business, benefits, chances of business created by the company or organization and total assets according to accessible yearly fiscal assets. It demonstrates that vision is basic for the wander or great development and performance of the organization, whereas recruitment ought to likewise line up with vision. Therefore, the organization will get higher out or execution. It has also inspected widely that vision essentially impacts on the procedure of methodology plan, assessment and performance of the organization's performance.

It is also adjusted during the time-spent recruitment so the likelihood to get inspiring future the management of organization will accomplish (Sabharwal, 2014). The worthiness of vision and in the long run effects of vision attributes on the satisfaction of staff that is still in early stages. The wonder in which top-level management verbalize the vision is according to the social limits of worker sentiments, behaviors, and feelings. At the same time, it is expected to check this connection experimentally. Successful visionary statement of an association is a basic medium to recognize the organization and employees' personality. By the strong vision, the present progress or development changes into a dynamic condition i.e. the upper hand for any organization (Hameed et al., 2014).

The accomplishment of basic vision increment the delightfulness of workers that showed the activity of group building forerunners and essentially it increases the dedication of worker on group or gathering level with hierarchical vision.

\subsection{Theoretical Framework}

This research investigated for one independent variable and one dependent variable. The independent variable includes Vision based recruitment here we break vision into no. of sub-particles i.e.; sharing of vision, clarity of vision, future orientation of vision, stability of vision and desirability of vision. While the organization's performance is the dependent variable.

\subsection{Hypothesis}

Following are the statement and the null hypothesis of this study:

H1: Vision clarity in the process of recruitment has positive effects on organizational 
performance.

H0: Vision clarity in the process of recruitment has negative effects on organizational performance.

$\mathrm{H} 2$ : Vision sharing on the time of recruitment has a positive effect on employee satisfaction, which leads to organizational performance.

H0: Vision sharing on the time of recruitment has a negative effect on employee satisfaction, which leads to organizational performance.

H3: Vision stability in recruitment positively affects organizational performance.

H0: Vision stability in recruitment negatively affects organizational performance.

H4: Vision desirability in recruitment positively affects organizational performance.

H0: Vision desirability in recruitment negatively affects organizational performance.

H5: Vision future orientation in employees positively affects organizational performance.

H0: Vision future orientation of employees negatively affects organizational performance.

\section{Research Methodology}

\subsection{Nature of Study}

This study is quantitative, exploratory, and prescient in nature. The essential information was gathered with the assistance of review questions, workers' diverse private organizations located in Pakistan matured approximately 18 and 50 through checked surveys. It is a cross-sectional and causal examination or study, which predicts the relationship and experimentally investigates the effect of the selected variables in this study. The researcher of this study distributed forms through Google form in the selected population/ sample organizations of Pakistan to get the quick results. This research method has been chosen because it is usually utilizing as a part of numerous exploration papers, which were investigated from the writing survey.

The second explanation behind choosing this strategy was the brief timeframe traverse and needed to gather information in the predefined time. Test gauge was 100 for this examination. (Hassan \& Sciences, 2016) proposed equation for figuring the example measure required for a multi-regression examination was utilized, where: $\mathrm{N} \geqslant 50+8 \mathrm{~m}$ where $(\mathrm{m})$ is the number of indicator factors (variable). In the measurements of this study, the measure of the autonomous variable was Six that is the reason the example estimate was resolved by; $50 \geqslant$ $8(5)=98$.

As per this condition, the slightest of 98 was considered as sufficient to avoid errors. Moreover, the researcher of this study circulated around 150 links of Google forms to various individuals working in various organizations that 102 were appropriately filled and submitted that generated $69 \%$ responses. 


\subsection{Instrument}

The instrument utilized for directing this examination was a questionnaire that was drifted online filled by respondents in various selected organizations of Pakistan.

\subsection{Instrument Development}

This research study is quantitative in nature. The essential information that was gathered was with the assistance of questionnaire, and the information was gathered from employees of various companies in the vicinity of 18 and 50 through checked surveys. The questionnaire formulation was in three phases; questions were first adjusted and changed for the specific subject under investigation after the development of the altered questionnaire.

Its face-legitimacy and content validity were checked with a specific end goal to discover the ease of use of the instrument utilized as a part of the examination and the gathered insights. The factors were taken from various sources i.e. Vision Clarity was taken from (Awan \& Farhan, 2016), Future Vision orientation was extracted from (Hafeez et al., 2015), Vision Stability extracted from (Imran et al., 2015), Desirability of vision was taken from (Saleem \& Khurshid, 2014), and sharing vision extracted from (Khan \& Rasheed, 2015).

\subsection{Face-Validity}

The face-legitimacy was finished by workers of the distinctive associations the surveys to both genders male and female orientations. Moreover, the changes were done to make the surveys simpler to comprehend and furthermore settle different mistakes in the survey questionnaire.

\subsection{Content Validity}

The content validity was guaranteed by the researcher of this study because the ethical consideration has been significantly considered during the survey. Moreover, the sample questionnaire was initially distributed among the experts in order to analyze its relevance to the topic. The variables selected by the researcher were surely related to the research theme and deviation from topic was highly evaded.

\subsection{Pilot Study}

Initially, a pilot examination of the survey was driven among the engaged gathering of focused people and the partners or stakeholders to start the study instrument.

\subsection{Tools and Techniques}

The statistics bundle IBM SPSS 21.0 was utilized to ascertain the regression and correlation investigation on the information gathered to discover the direction and magnitude of the research study.

\section{Data Analysis}

For examining at the unwavering quality the created instrument, SPSS programming was utilized in order to figure Cronbach's Alpha with respect to the factors of the investigation; 
Clarity of Vision, Sharing of Vision, Vision Stability, Desirability of Vision, Desirability of Vision Future Orientation of Vision and Organization's Performance. (Ekwoaba et al., 2015) expressed that Cronbach's Alpha coefficient must be bigger than 0.7 in order to be more reliable and solid. The process Cronbach's Alpha coefficients in this examination for dependent and independent factors (variables) were, Clarity of Vision: 0.753, Sharing of Vision: 0.563, Vision Stability: 0.636, Desirability of Vision: 0.724, Future Orientation of Vision: 0.773 and Organization's Performance: 0.786 (see Table 1).

In this research study, the aggregate number of members who participated was 102 since the investigation was only on representatives of various organizations vision oriented recruitment of employees were interviewed in the form of questionnaires. The age bunch differs from 18 to 50 . From the age gathering of $18-25$, the respondents were 28 ; there were 54 respondents from the age gathering of 26-30. In the same manner, the age gathering of 31-40 comprised of 15 respondents. From 41- 50 there were 05 members. The examination uncovered that the academic level of 64 respondents was Graduate, while 35 were Post Graduates and 03 respondents were undergraduate (see Table 2).

In Table 3, the outcomes (result) were figured for every factor (variable). As indicated by the clear descriptive examination of research, the least reactions for every variable were 1 while most extreme reactions were 5 and 4. The mean for Clarity of Vision is 1.92 and the standard deviation for it is 0.66 . The mean for Sharing of Vision is 2.25 and the standard deviation for it is 0.56 . The mean for Vision Stability y is 2.28 and the standard deviation for it is 0.64 . The mean for Desirability of Vision is 2.33 and the standard deviation for it is 0.75 . The mean for Future Orientation of Vision is 2.24 and the standard deviation for it is 0.74 . The mean for Organization's Performance is 2.30 and the standard deviation is 0.78 .

Correlation examinationlanalysis essentially states about the quality and directions of factors (variables) with each other. In statistical analysis, "r" speaks to the Pearson correlation coefficient. It can either be utilized to quantify the relationship between one independent factor (variable) and another independent factor (variable) or between independent factors (variable) with the dependent factor (variable). It is just anxious about the quality of the relationship. The relationship can either be certain or negative. On the off chance that the Pearson correlation coefficient, " $r$ " is nearer to - 1, it implies there is a solid negative direct relationship and in the event that it is nearer 1 it implies there is a solid positive straight relationship. To ponder the connections between the independent factors; Clarity of Vision, Sharing of Vision, Vision Stability, Desirability of Vision, Future Orientation of Vision and Organization's Performance.

Table 4 Shows the relationship between' the reliant variable and autonomous factors, the table demonstrates that there is a positive correlation between the dependent factor(variable) that is Organization's Performance and clearness of Vision with an esteem (value) having 0.507. The relationship between Sharing of Vision and Organization's Performance is additionally direct positive in nature having 0.476 which demonstrates that in spite of the fact that there is a positive correlation, Vision Stability is additionally direct positive correlation with 0.515 with high hugeness. Attractive quality of Vision with a coefficient of .644 with a centrality is 
significance up to $99 \%$. Future Orientation of Vision has the most noteworthy correlation with the Organization's Performance with a Pearson correlations' coefficient of 0.710 and importance level-up to $99 \%$.

Table 5 highest coefficient of correlation is of Future Orientation of Vision and minimum coefficient of correlation is for Sharing of Vision. This adds up that Future Orientation of Vision has maximal effect on Organization's Performance of employees of Pakistan regarding apparel. Other variables like the clarity of Vision, Vision Stability, and Desirability of Vision also have a pleasant effect on the performance of Organization and Sharing of Vision has a low effect on the organization of Pakistan.

Table 6 demonstrates that $\mathrm{R}$ square is .542 and accommodate $\mathrm{R}$ square is .518 that is around $52 \%$. It clarifies that the dependent factor (variable) has $52 \%$ of the impact on the dependent variable and chance of change in a single variable like independent variable brings about changes in dependent factors (variable) other $48 \%$ of changes are because of the obscure and unclear factors. In Table 7, it has been discovered that the model that is being utilized as a part of this examination is fit since the essentialness esteem value is .000 with the goal that confirms that the exploration has been done on substantial grounds.

The coefficients' of Table 8 demonstrate that the significance of t-value is that if the t-value is over 1 and noteworthiness is under 0.05 then the hypothesis of the study will be acknowledged however in the event that the $t$-value is lesser than 2 and importance is more noteworthy than 0.05 then the hypothesis will be rejected. In the table, H0 is dismissed (rejects) as every one of the factors has an organization' with organization's performance, H1 is acknowledged because the coefficient demonstrates that there is a relation between the factors (variable). $\mathrm{H} 2$ has t-value of 0.038 which is underneath 1 and significance is 0.970 which is over 0.05 . H3 has a t-value of 0.738 which is beneath 1 and significance is 0.462 which is over 0.05 . $\mathrm{H} 4$ has a t-value of -0.011 which is underneath 1 and significance is 0.992 which is over 0.05. So H2, H3, H4 are dismissed separately and H5, H6 are acknowledged as H5 has a t-value of 2.094 which is over 1 and noteworthiness is 0.039 which is beneath 0.05 and $\mathrm{H} 6$ has a t-value is 4.401 which is over 1 and centrality is 0.000 which is under 0.05 .

\section{Discussions and Analysis}

The reason for this exploration was to find the effect, size and directions of independent variables (Clarity of Vision, Sharing of Vision, Vision Stability, Desirability of Vision, Future Orientation of Vision) on the dependent variable (Organization's Performance) that were recognized after a broad review of the literature. It is investigated in this study that the most significant factors that affect the organization performance are Future Orientation of Vision and Desirability of Vision. Although other variables show a positive relationship with the organization performance but they are slightly weaker than these two variables. Therefore, it can be stated that organization performance is more affected if the employees have a future orientation of vision and desirability of vision. Hence, it is mandatory to work on these aspects and deeply focused on these aspects at the time of recruitment. In this way, this investigation demonstrated that most respondents were from 26-30 and graduate understudies, 
so investigation underlines more on the general population who are doing work in various organizations. Consequently, it has been said that this examination analyzed the impact of Future Orientation of Vision and Desirability of Vision on the recruitment process i.e. more effective as vision clarity or stability of vision. Moreover, it has been analyzed that the recruitment without vision-based aspects cannot produce better outcomes of organizational performance. In this way, the vision-based recruitment is signified as a more valuable asset of any organization is human resources that have a high influence on organizational performance.

\subsection{Suggestions}

This research study can help the Recruitment $\backslash$ HR managers' in any public or private sector to design their recruitment strategies that are aligned with the vision of the company and covers all the aspects cover in the vision and help their company progress in the right direction. This exploration is signified as a strong model for additional research in related areas such as the employee citizenship behaviors, recruitment, and strategic vision, and learning of employees with respect to vision breakups in Pakistan. Organization vision based recruitment approaches in an organization is indicated by the aftereffects of this examination. The organizations would know how much vision perspectives during recruitment ought to be placed in various dimensions' is important to get an expanded organizational productivity and performance.

\section{Conclusion}

The purpose of this study was to identify them, "impact of vision based recruitment on organization's performance in Pakistan". Six variables were identified i.e., Clarity of Vision, Sharing of Vision, Vision Stability, Desirability of Vision, Future Orientation of Vision and Organization's Performance, in which the organization performance is the dependent variable while other is the independent variable. The research exhibit that Future Orientation of Vision and Desirability of Vision was the only factor of vision based recruitment that affected organization performance. In Pakistan, the vision-based recruitment is very rare to observe in any organization. It is important for Pakistan to adopt vision-based recruitment so that the industries and organizations situated in Pakistan get high organizational performance. No research has been done previously in Pakistan, which explores vision based recruitment and its impact on Pakistani's organization.

It is concluded that the staff of an organization can express their appreciation for the importance of expressing a vision, as well as directs knowledge if they know the organization vision during recruitment. However, the human resource management must take the necessary precautions to inform them more frequently while recruiting them. It has been decided that the administration must give a specific thought to where these statements will be published; thus, create the necessary influence on the organization performance. The most popular aspect to inform the vision of an organization to all individual is possible by the vision-based recruitment. These initiatives will direct and motivate the employees towards the aims and objectives of an organization and get their jobs to be done accordingly, should be explored to improve traditional initiatives. 


\section{Mll Macrothink}

International Journal of Human Resource Studies

ISSN 2162-3058

2018, Vol. 8, No. 4

Despite the apparently high data levels and the purpose of vision, most employees do not have a good knowledge of the components/contents of the task statement that requires intervention. For the desired results, the components are suggested to measurable models by introducing clarity of vision, sharing of vision, vision stability, the desirability of vision, the future orientation of vision, so staff will follow it. Such an effort also allows the management to get the more motivated and delegated employees toward their roles and responsibilities according to the organizational tasks' requirement.

The human resource management has to identify more influential vision based recruitment in the organization of Pakistan in order to recruit skillful employees. This will help them to get delegated employees into an organization according to their organizational tasks. This will only possible by clarifying the vision and mission of the organization to them. Hence, they have to identify their vision during the recruitment process to identify the more skillful employee. This will also help the employee to understand their roles and responsibilities of the job more clarify by considering the structured organization vision.

\section{Acknowledgement}

Above all else thank to Almighty "ALLAH" who is most tolerant and kind to the majority of his manifestations with no segregation and who makes me ready to set up this research report.

I generously appreciative to my research supervisor, Sir Danish, whose consolation, help and support from the initial step to the last level empowered me to build up an understanding of the methodology of conducting research and empowered me to build up a comprehension of the approach of leading exploration.

My research work has benefited from the insightful direction of numerous colleagues, teachers, employees and more numerous than I can fully acknowledge here. I would like to acknowledge those who participated in the occasions that I conducted interviews to get formal feedback on my research topic that is "Impact of Vision Based Recruitment On Organization's Performance in Pakistan"

Finally, I offer my respects and endowments to all those who supported and promoted me in any regard amid the fulfilment of the research.

\section{References}

Ahmed, S., Fiaz, M., \& Shoaib, M. J. F. J. o. S. S. (2015). Impact of knowledge management practices on organizational performance: an empirical study of banking sector in Pakistan. 9(2), 147-167.

Altinay, L., Madanoglu, M., De Vita, G., Arasli, H., \& Ekinci, Y. (2016). The interface between organizational learning capability, entrepreneurial orientation, and SME growth. Journal of Small Business Management, 54(3), 871-891.

Arshad, A., Azhar, S., \& Khawaja, K. (2014). Dynamics of HRM practices and organizational performance: quest for strategic effectiveness in Pakistani organizations.

Aslam, U., Ilyas, M., Imran, M. K., \& Rahman, U. (2016). Intelligence and its impact on managerial effectiveness and career success (evidence from insurance sector of Pakistan). 
Journal of Management Development, 35(4), 505-516. https://doi.org/10.1108/JMD-10-2015-0153

Asrar-ul-Haq, M., \& Kuchinke, K. P. (2016). Impact of leadership styles on employees' attitude towards their leader and performance: Empirical evidence from Pakistani banks. Future Business Journal, 2(1), 54-64. https://doi.org/10.1016/j.fbj.2016.05.002

Asrar-ul-Haq, M., Kuchinke, K. P., \& Iqbal, A. J. J. o. C. P. (2017). The relationship between corporate social responsibility, job satisfaction, and organizational commitment: Case of Pakistani higher education, 142, 2352-2363.

Awan, A. G., \& Farhan, H. M. J. S. I. (2016). Talent Management Practices And Their Impact On Job Satisfaction Of Employees: A Case Study Of Banking Sector In Pakistan. 28(2), 1950.

Azeem, M. M., Abrar, M., Bashir, M., \& Zubair, A. (2015). Impact of organizational justice and psychological empowerment on perceived organizational performance: The mediating role of organizational citizenship behaviour. American Journal of Industrial and Business Management, 5(05), 272. https://doi.org/10.4236/ajibm.2015.55029

Bisharat, H., Obeidat, B. Y., Tarhini, A., Mukattash, I. J. I. J. o. B., \& Management. (2016). The effect of human resource management practices on organizational commitment in chain pharmacies in Jordan. 12(1), 50.

Dhar, B., Rahouma, H., Masruki, R., \& Absar, M. (2017). Impact of Islamic Human Resource Practices on Organizational Performance through Organizational Commitment in the Banking Sector of Bangladesh. Paper presented at the 7th Islamic Economic System Conference, Sultanate of Oman.

Ekwoaba, J. O., Ikeije, U. U., \& Ufoma, N. (2015). The Impact of Recruitment and Selection Criteria on Organizational Performance.

Hafeez, U., \& Akbar, W. (2015). “Impact of Training on Employees Performance”(Evidence from Pharmaceutical Companies in Karachi, Pakistan). Business Management and Strategy, 6(1), 49-64. https://doi.org/10.5296/bms.v6i1.7804

Hameed, A., Ramzan, M., \& Zubair, H. M. K. (2014). Impact of compensation on employee performance (empirical evidence from banking sector of Pakistan). International Journal of Business and Social Science, 5(2).

Haroon, U., \& Shariff, M. N. M. (2016). The interplay of innovation, TQM practices and SMEs performance in Pakistan: moderating effects of knowledge inertia and external environment. South East Asia Journal of Contemporary Business, Economics and Law, 9(2).

Hassan, S. J. I. J. o. A. R. i. A., Finance, \& Sciences, M. (2016). Impact of HRM practices on employee's performance. 6(1), 15-22.

Imran, M., \& Tanveer, A. (2015). Impact of training \& development on employees' performance in banks of pakistan. European Journal of Training and Development Studies, $3(1), 22-44$. 


\section{Macrothink}

International Journal of Human Resource Studies

ISSN 2162-3058

2018, Vol. 8, No. 4

Iqbal, N., Nadeem, W., \& Zaheer, A. (2015). Impact of BPR critical success factors on inter-organizational functions: an empirical study. The Business \& Management Review, 6(1), 152.

Khan, A. S., \& Rasheed, F. (2015). Human resource management practices and project success, a moderating role of Islamic Work Ethics in Pakistani project-based organizations. International Journal of Project Management, 33(2), 435-445. https://doi.org/10.1016/j.ijproman.2014.08.006

Pak, J., \& Kim, S. (2018). Team manager's implementation, high performance work systems intensity, and performance: a multilevel investigation. Journal of management, 44(7), 2690-2715. https://doi.org/10.1177/0149206316646829

Rana, M. H., \& Malik, M. S. (2017). Impact of human resource (HR) practices on organizational performance: Moderating role of Islamic principles. International Journal of Islamic and Middle Eastern Finance and Management, 10(2), 186-207. https://doi.org/10.1108/IMEFM-04-2016-0060

Rizwan, M., Khan, M. N., Nadeem, B., \& Abbas, Q. (2016). The impact of workforce diversity towards employee performance: Evidence from banking sector of Pakistan. American Journal of Marketing Research, 2(2), 53-60.

Sabharwal, M. (2014). Is diversity management sufficient? Organizational inclusion to further performance. Public Personnel Management, 43(2), 197-217. https://doi.org/10.1177/0091026014522202

Saleem, I., \& Khurshid, A. (2014). Do human resource practices affect employee performance?.

Yousaf, A., Yang, H., \& Sanders, K. (2015). Effects of intrinsic and extrinsic motivation on task and contextual performance of Pakistani professionals: the mediating role of commitment foci. Journal of Managerial Psychology, 30(2), 133-150. https://doi.org/10.1108/JMP-09-2012-0277

\section{Appendix}

Table 1. Reliability Statistics

Reliability of Variables

\begin{tabular}{lcc}
\hline Constructs & $\begin{array}{c}\text { Number } \\
\text { of Items }\end{array}$ & $\begin{array}{c}\text { Cronbach's } \\
\text { alpha }\end{array}$ \\
\hline Clarity of Vision & 3 & .753 \\
$\begin{array}{l}\text { Sharing of Vision } \\
\text { Vision Stability }\end{array}$ & 3 & .563 \\
$\begin{array}{l}\text { Desirability of } \\
\text { Vision }\end{array}$ & 3 & .636 \\
$\begin{array}{l}\text { Future Orientation } \\
\text { of Vision }\end{array}$ & 3 & .724 \\
$\begin{array}{l}\text { Organization's } \\
\text { Performance: }\end{array}$ & 3 & .773 \\
\hline
\end{tabular}


Table 2. Demographic Data

Demographic Analysis

\begin{tabular}{lll}
\hline Demographics & \multicolumn{1}{c}{$\begin{array}{c}\text { of } \\
\text { Respondents }\end{array}$} \\
\hline \multirow{3}{*}{ Age } & $18-25$ & 27.5 \\
& $26-30$ & 52.9 \\
Education & $31-40$ & 14.7 \\
& $41-50$ & 4.9 \\
\hline \multirow{4}{*}{ Type } & Graduate & 62.7 \\
Industry & Post Graduate & 34.3 \\
& Undergraduate & 2.9 \\
\hline & Advertising & 15.7 \\
& Banking & 18.6 \\
& Defense Services & 2.9 \\
& Education & 13.7 \\
& Govt & 1.0 \\
& Health Sector & 8.8 \\
& Hotel & 1.0 \\
& IT & 6.9 \\
& Manufacturing & 11.8 \\
& NGO & 2.9 \\
\hline
\end{tabular}

Table 3. Descriptive Statistics

Descriptive Statistics of Variables

\begin{tabular}{llllll}
\hline & $\mathbf{N}$ & Min & Max & Mean & SD \\
\hline Clarity of Vision & 102 & 1 & 5 & 1.92 & 0.66 \\
Sharing of Vision & 102 & 1 & 3.67 & 2.25 & 0.56 \\
$\begin{array}{l}\text { Vision Stability } \\
102\end{array}$ & 1 & 5.00 & 2.28 & 0.64 \\
$\begin{array}{l}\text { Desirability of } \\
\text { Vision }\end{array}$ & 102 & 1 & 4.67 & 2.33 & 0.75 \\
$\begin{array}{l}\text { Future Orientation } \\
\text { of Vision }\end{array}$ & 102 & 1 & 4.67 & 2.24 & 0.74 \\
Organization's & & & & & \\
\begin{tabular}{l} 
Performance \\
\hline
\end{tabular} & 102 & 1 & 4.33 & 2.30 & 0.78 \\
\hline
\end{tabular}


Table 4. Correlation analysis of Clarity of Vision, Sharing of Vision, Vision Stability, Desirability of Vision, Future Orientation of Vision and Organization's Performance

\begin{tabular}{|c|c|c|c|c|c|c|c|}
\hline & & $\begin{array}{l}\text { Clarity } \\
\text { of } \\
\text { Vision }\end{array}$ & $\begin{array}{c}\text { Sharing } \\
\text { of } \\
\text { Vision }\end{array}$ & $\begin{array}{c}\text { Vision } \\
\text { Stability }\end{array}$ & $\begin{array}{c}\text { Desirability } \\
\text { of Vision }\end{array}$ & $\begin{array}{c}\text { Future } \\
\text { Orientation } \\
\text { of Vision }\end{array}$ & $\begin{array}{c}\text { Organization's } \\
\text { Performance }\end{array}$ \\
\hline \multirow[t]{2}{*}{$\begin{array}{l}\text { Clarity of } \\
\text { Vision }\end{array}$} & $\begin{array}{l}\text { Pearson } \\
\text { Correlation } \\
\text { Sig. } \\
\text { (2-tailed) }\end{array}$ & 1 & & & & & \\
\hline & $\mathrm{N}$ & 102 & & & & & \\
\hline \multirow[t]{2}{*}{$\begin{array}{l}\text { Sharing of } \\
\text { Vision }\end{array}$} & $\begin{array}{l}\text { Pearson } \\
\text { Correlation } \\
\text { Sig. } \\
\text { (2-tailed) }\end{array}$ & .000 & 1 & & & & \\
\hline & $\mathrm{N}$ & 102 & 102 & & & & \\
\hline \multirow[t]{3}{*}{$\begin{array}{l}\text { Vision } \\
\text { Stability }\end{array}$} & $\begin{array}{l}\text { Pearson } \\
\text { Correlation }\end{array}$ & $.501^{* *}$ & $.646^{* *}$ & 1 & & & \\
\hline & $\begin{array}{l}\text { Sig. } \\
\text { (2-tailed) }\end{array}$ & .000 & .000 & & & & \\
\hline & $\mathrm{N}$ & 102 & 102 & 102 & & & \\
\hline \multirow[t]{3}{*}{$\begin{array}{l}\text { Desirability of } \\
\text { Vision }\end{array}$} & $\begin{array}{l}\text { Pearson } \\
\text { Correlation }\end{array}$ & $.619^{* *}$ & $.602^{* *}$ & $.632^{* *}$ & 1 & & \\
\hline & $\begin{array}{l}\text { Sig. } \\
\text { (2-tailed) }\end{array}$ & .000 & .000 & .000 & & & \\
\hline & $\mathrm{N}$ & 102 & 102 & 102 & 102 & & \\
\hline \multirow{3}{*}{$\begin{array}{l}\text { Future } \\
\text { Orientation of } \\
\text { Vision }\end{array}$} & $\begin{array}{l}\text { Pearson } \\
\text { Correlation }\end{array}$ & $.649^{* *}$ & $.524^{* *}$ & $.640^{* *}$ & $.727^{* *}$ & 1 & \\
\hline & $\begin{array}{l}\text { Sig. } \\
\text { (2-tailed) }\end{array}$ & .000 & .000 & .000 & .000 & & \\
\hline & $\mathrm{N}$ & 102 & 102 & 102 & 102 & 102 & \\
\hline \multirow[t]{3}{*}{$\begin{array}{l}\text { Organization's } \\
\text { Performance }\end{array}$} & $\begin{array}{l}\text { Pearson } \\
\text { Correlation }\end{array}$ & $.507^{* *}$ & $.476^{* *}$ & $.515^{* *}$ & $.644^{* *}$ & $.710^{* *}$ & 1 \\
\hline & $\begin{array}{l}\text { Sig. } \\
\text { (2-tailed) }\end{array}$ & .000 & .000 & .000 & .000 & .000 & \\
\hline & $\mathrm{N}$ & 102 & 102 & 102 & 102 & 102 & 102 \\
\hline
\end{tabular}

**. Correlation is significant at the 0.01 level (2-tailed). 
Table 5. Correlations

\begin{tabular}{lll}
\hline Variables & $\mathrm{R}$ & Sig \\
\hline Clarity of Vision & $.507^{* *}$ & .000 \\
Sharing of Vision & $.476^{* *}$ & .000 \\
Vision Stability & $.515^{* *}$ & .000 \\
Desirability of Vision & $.644^{* *}$ & .000 \\
Future Orientation of & $.710^{* *}$ & .000 \\
Vision & \\
\hline
\end{tabular}

Table 6. Model Summary

\begin{tabular}{lllll}
\hline Model & $\mathrm{R}$ & R Square & Adjusted R Square & Sig F change \\
\hline 1 & $.736^{\mathrm{a}}$ & .542 & .518 & .000 \\
\hline
\end{tabular}

Table 7. ANOVA ${ }^{\mathrm{a}}$

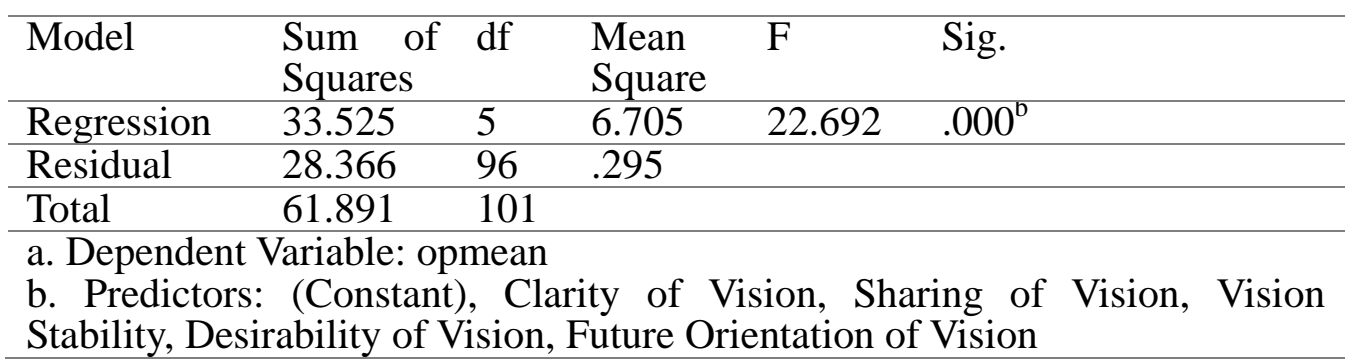

Table 8: Coefficients

\begin{tabular}{lllllll}
\hline Model & B & \multicolumn{2}{c}{ Std. Error } & Beta & T & Sig \\
\hline & (Constant) & .311 & .240 & & 1.300 & .197 \\
Clarity of Vision & .004 & .113 & .004 & .038 & .970 \\
& $\begin{array}{l}\text { Sharing of Vision } \\
\text { Vision Stability }\end{array}$ & .100 & .135 & .071 & .738 & .462 \\
& $\begin{array}{l}\text { Desirability of } \\
\text { Vision }\end{array}$ & .247 & .118 & .237 & 2.094 & .039 \\
& $\begin{array}{l}\text { Future Orientation } \\
\text { of Vision }\end{array}$ & .528 & .120 & .499 & 4.401 & .000 \\
\hline
\end{tabular}

a. Dependent Variable: Organization's Performance

\section{Copyright Disclaimer}

Copyright for this article is retained by the author(s), with first publication rights granted to the journal.

This is an open-access article distributed under the terms and conditions of the Creative Commons Attribution license (http://creativecommons.org/licenses/by/4.0/). 